\title{
Nyctaginaceae endémicas del Perú
}

\section{Blanca León ${ }^{1,2}$}

${ }^{1}$ Museo de Historia Natural, Av. Arenales 1256, Aptdo. 14-0434, Lima 14, Perú

2 Plant Resources Center, University of Texas at Austin, Austin TX 78712 EE.UU.

blanca.leon@mail.utexas.edu

\section{Resumen}

La familia Nyctaginaceae es reconocida en el Perú por presentar once géneros y 53 especies (Brako \& Zarucchi, 1993; Ulloa Ulloa et al., 2004), la mayoría arbustos y hierbas. En este trabajo reconocemos cinco especies endémicas en tres géneros. Las especies endémicas se encuentran principalmente en las regiones Desierto Cálido Tropical y Matorral Desértico, entre los 100 y 2400 m de altitud. Aparentemente, ninguna endémica se encuentra representada dentro del Sistema Nacional de Áreas Naturales Protegidas por el Estado.

Palabras claves: Nyctaginaceae, Perú, endemismo, plantas endémicas.

\section{Abstract}

The Nyctaginaceae are represented in Peru by eleven genera and 53 species (Brako \& Zarucchi, 1993; Ulloa Ulloa et al., 2004), mostly shrubs and herbs. Here we recognize five endemic species, which are found mainly in Tropical Costal Desert and Desert Shrubland regions, between 100 and 2400 m elevation. Apparently, no endemic species of Nyctaginaceae have been recorded within Peru's protected areas system.

Keywords: Nyctaginaceae, Peru, endemism, endemic plants.

\section{Boerhavia verbenaceae Killip}

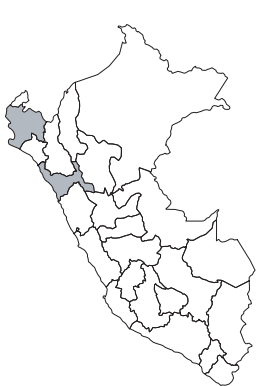

\section{DD}

Publicación: J. Wash. Acad. Sci. 16: 567. 1926.

Colección tipo: O. Haught 8

Herbarios: US.

Nombre común: Desconocido,

Registro departamental: LL, PI.

Regiones Ecológicas: DCT; $100-250 \mathrm{~m}$

SINANPE: Sin registro.

Herbarios peruanos: CPUN (4).

Observaciones: Hierba anual, conocida de unas pocas localidades dispersas en la costa norte del país. Aparentemente todos los ejemplares de herbario conocidos fueron realizados durante eventos «El Niño». Poco se sabe de su biología y la extensión de sus poblaciones. Al parecer esta especie es coespecífica con Boerbavia weberbaueri.

\section{Boerhavia weberbaueri Heimerl}

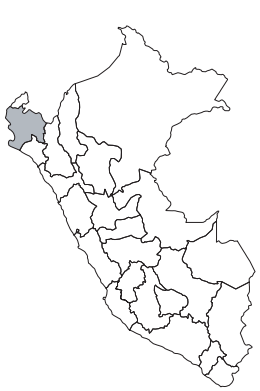

NE

Publicación: Notizbl. Bot. Gart. BerlinDahlem 11: 460. 1932.

Colección tipo: A. Weberbauer 5933

Herbarios:

Nombre común: Desconocido,

Registro departamental: PI.

Regiones Ecológicas: DCT; $100-250 \mathrm{~m}$. SINANPE: Sin registro.

Herbarios peruanos: Ninguno.

Observaciones: Hierba de taxonomía incierta. Esta especie parece ser coespecífica con Boerhavia verbenaceae, la cual es considerada endémica. Al igual que esa especie, es conocida de la costa norte del país, es una planta anual y la inflorescencia es larga.

\section{Mirabilis campanulata Heimerl}

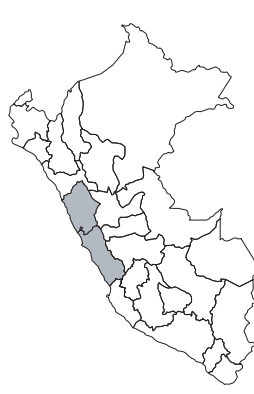

\section{NE}

Publicación: Bot. Jahrb. Syst. 42: 75. 1908. Colección tipo: A. Weberbauer 3198

Herbarios: B.

Nombre común: Desconocido.

Registro departamental: AN, LI.

Regiones Ecológicas: MDE, MA; 2000$3000 \mathrm{~m}$.

SINANPE: Sin registro.

Herbarios peruanos: Ninguno,

Observaciones: Hierba conocida de unas pocas localidades dispersas, en la vertiente occidental. Esta especie cuenta con escaso registro de herbario. El ejemplar tipo proviene de la cuenca del Casma y fue recolectado en 1903. Otra localidad conocida se halla en la cuenca del Rímac. Se requiere aclarar su vínculo con Mirabilis weberbaneri.

\section{Mirabilis weberbaueri Heimerl}

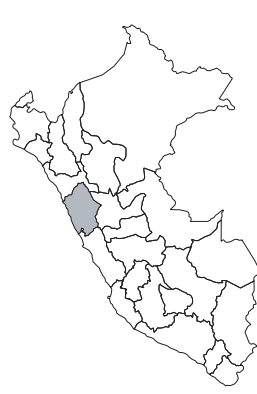

NE

Publicación: Bot. Jahrb. Syst. 42: 73. 1908. Colección tipo: A. Weberbauer 3185

Herbarios: B; MOL!

Nombre común: Desconocido.

Registro departamental: AN.

Regiones Ecológicas: MDE; 2100—2400

SINANPE: Sin registro.

Herbarios peruanos: MOL (isotipo).

Observaciones: Hierba postrada, conocida, al parecer, de una sola localidad en la vertiente del Pacífico de la Cordillera Negra, cuenca del Casma. Podría ser coespecífica con Mirabilis campanulata. 


\section{Neea williamsii Standl.}

\section{DD}

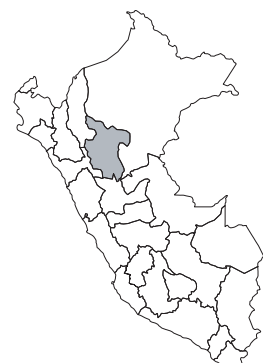

Publicación: Publ. Field Columbian Mus., Bot. Ser. 8(5): 309. 1931.

Colección tipo: L. Williams 6567

Herbarios: F.

Nombre común: Desconocido.

Registro departamental: SM.

Regiones Ecológicas: BMHP, BHA; $360-900 \mathrm{~m}$

SINANPE: Sin registro.

Herbarios peruanos: Ninguno.

Observaciones: Arbusto conocido aparentemente sólo de la colección tipo, una planta recolectada en 1909, de la cuenca del Mayo, la cual, a la altura de la localidad original, está afectada por la deforestación. 